\title{
Proposta de framework para avaliar o desempenho de organizaç̧ões do terceiro setor
}

\section{Framework proposal to evaluate the performance of organizations in the third}

\author{
sector

\begin{abstract}
Marcelo Medeiros da Rosa Mestre em Contabilidade.Universidade Federal de Santa Catarina (UFSC) - Brasil. mmr2801@yaho0.com.br Sérgio Murilo Petri Doutor em Engenharia de Produção. Universidade Federal de Santa Catarina (UFSC - Brasil.
\end{abstract} \\ smpetri@gmail.com.
}

\begin{abstract}
RESUMO
As mudanças organizacionais, decorrentes da globalização e constante evolução tecnológica, exigem maior dinamismo, responsabilidade e adaptabilidade das organizações na tentativa de se manterem ativas e operando. Tais mudanças, iniciadas no século XX, somadas à deficiência do Estado no atendimento de seus governados e o aumento da participação da sociedade civil nas demandas sociais, proporcionaram o crescimento das organizações do terceiro setor. O objetivo deste estudo é construir uma proposta de framework para avaliar o desempenho das organizações do terceiro setor. Em termos metodológicos, a pesquisa é qualitativa, de lógica dedutiva, aplicada e a fonte de dados utilizada foi a secundária. É apresentada a proposta de framework para avaliar o desempenho de organizações do terceiro setor estabelecida em quatro fases (contextualização, estruturação, avaliação e propor aperfeiçoamentos). A proposta buscou integrar a missão, os stakeholders e estratégias com os elementos de avaliação do desempenho organizacional no terceiro setor, além de incorporar aspectos de outras metodologias de avaliação de desempenho, tais como (i) o envolvimento dos stakeholders, (ii) a indicação das perspectivas a serem utilizadas; (iii) a inclusão de aspectos relacionados às capacidades da organização; e (iv) a possibilidade da proposta de modelo ser útil para monitorar e melhorar o desempenho. Outrossim, propõe-se o uso de escalas cardinais de intervalo na avaliação do desempenho, que agregam a quantificação da diferença entre os níveis da escala, situação que eleva o nível de conhecimento gerado e torna o processo de tomada de decisão das organizações do terceiro setor fundamentado em informações verossímeis.
\end{abstract}

Palavras-chave: Avaliação de Desempenho. Terceiro Setor. Tomada de Decisão.

\begin{abstract}
Organizational changes, resulting from globalization and constant technological evolution, require greater dynamism, responsibility and adaptability of organizations in an attempt to remain active and operating. These changes, which began in the twentieth century, added to the deficiency of the State in serving its governed and the increasing participation of civil society in social demands, allowed for the growth of Third Sector organizations. The objective of this study is to propose a framework to evaluate the performance of third sector organizations. In methodological terms, the research is qualitative, of deductive logic, applied and the source of data used was secondary. The proposed framework for evaluating the performance of third sector organizations established in four phases (contextualization, structuring, evaluation and proposing improvements) is presented. The proposal sought to integrate the mission, stakeholders and strategies with the elements of evaluation of organizational performance in the third sector, as well as to incorporate aspects of other performance evaluation methodologies, such as (i) stakeholder involvement; (ii) indication of the perspectives to be used; (iii) the inclusion of aspects related to the organization's capabilities; and (iv) the possibility of the model proposal being useful for monitoring and improving performance. It is also proposed the use of cardinal interval scales in the performance evaluation, which aggregates the quantification of the difference between the levels of the scale, a situation that raises the level of knowledge generated and makes the decision-making process of the organizations of the Third Sector based on credible information.
\end{abstract}

Keywords: Performance evaluation. Third sector. Decision Making. 


\section{INTRODUÇÃO}

As frequentes mudanças no ambiente organizacional têm exigido maior dinamismo, responsabilidade e adaptabilidade na construção de um diferencial competitivo sustentável. Esta vantagem impulsiona as organizações na tentativa de se manterem no mercado por um maior período de tempo possível.

Além disso, a deficiência do Estado na promoção de serviços públicos e o novo papel exercido pela sociedade, de corresponsável pelas demandas sociais, são fatores que contribuíram para o crescimento e fortalecimento de organizações do terceiro setor que surgiram como parte da solução dos problemas sociais. (MOXHAM, 2009; PAULA; BRASIL; MARIO,2009; QUINTAIROS et al. 2009; HELMIG; INGERFURTH; PINZ, 2014; ARENA; AZZONE; BENGO, 2015; ROSA et al. 2016).

Na medida que as organizações vinculadas ao terceiro setor têm uma importância significativa na sociedade e na economia contemporânea, cresce também a exigência para que estas demonstrem a sua eficácia. Para Lebarcky et al. (2010), graças às origens e objetivos, muitas vezes associadas a iniciativas de autogestão e a movimentos voltados a questões sociais, as organizações deste setor desenvolveram resistência à adoção de práticas de gestão, vistas como ferramentas do setor privado.

Mesmo as empresas com fins lucrativos reconheceram recentemente que uma abordagem (ou metodologia) de avaliação do desempenho que utiliza apenas medidas financeiras é inadequado para medir o desempenho organizacional. Demonstrações contábeis medem desempenho passado e pouco comunicam sobre a criação de valor no longo prazo (KAPLAN, 2001; LIMA; SOARES; LIMA, 2011).

Para remediar esta lacuna, abordagens e metodologias originadas do setor privado foram adaptadas para a realidade das organizações do terceiro setor. Entretanto, poucas abordagens integram diferentes medidas de desempenho relevantes, que incorporem múltiplas dimensões para entidades sem fins lucrativos, embora iniciativas de avaliação de programas tenham sido lançadas (MEDINA-BORJA; TRIANTIS, 2007).

Observadas as peculiaridades dessas entidades, o problema de investigação proposta é: Quais as etapas de um framework para a avaliação do desempenho das organizações do terceiro setor?

A partir desta questão, o objetivo geral foi de construir uma proposta de framework para avaliar o desempenho das organizações do terceiro setor.

O presente artigo, além da introdução, contém mais quatro seções. Na segunda, encontra-se o referencial teórico. Na terceira seção é apresentada a metodologia utilizada no estudo. A quarta, constitui-se na apresentação de resultados e a quinta e última seção refere-se às considerações finais.

\section{TERCEIRO SETOR}

Embora grupos organizados que atuam na prestação de serviços sociais e assistenciais existissem há milhares de anos, como a Igreja Católica, foi apenas a partir da década de 1950 que passaram a ter reconhecimento da sociedade com a criação do Nonprofit Sector, ou Setor Sem Fins Lucrativos. Este setor se caracterizava por ações de caridade, financiadas por doações voluntárias e com estreitas relações com os ideais da livre iniciativa, do filantropismo e do associativismo da população norte-americana ( MILLAR; HALL, 2013).

Esse tipo de atividade não estatal, criada a partir da impossibilidade do Estado de solucionar os problemas que se agravaram a partir das mudanças dos contextos social e econômico ocorridas desde a Revolução Industrial recebeu a terminologia de Third Sector, ou Terceiro Setor, pois não se encaixavam nas características jurídicas, econômicas e de atuação dos entes estatais, tampouco os do mercado.

No Brasil, as primeiras discussões sobre o tema surgiram na época do regime militar, período que as instituições de caráter filantrópico e assistencial se uniram aos movimentos sociais e, com o apoio das Comunidades Eclesiais de Base, passam a atuar em situações de repressão e perseguição política e desigualdade e injustiça social.

De acordo com Lebarcky et al. (2009), até o final da década de 1980 o trabalho das organizações do terceiro setor consistia em ações isoladas, de caráter assistencialista e sem grandes pretensões. Com o passar dos anos, ganharam relevância pela formalização e pelo reconhecimento que seus atos impactam 
diretamente em aspectos sociais, culturais, econômicos e políticos na sociedade, representando a vitalidade e a saúde das sociedades democráticas, constituindo-se como uma arena importante para a comunicação humana, onde as diferentes opiniões são alinhadas entre si (TENÓRIO, 1999; LINDGREN; 2001; SMITH, 2005).

Apesar de sua controvérsia conceitual, estes estudos perpassam vários temas, como caridade, voluntariado, economia social e entre outros. Posto tal dicotomia, faz-se necessária a apresentação da visão dos pesquisadores sobre o terceiro setor e suas características.

\subsection{Conceito e Características}

De acordo com Pereira et al. (2013), a definição de terceiro setor é controversa. Tido muitas vezes por pesquisadores como um setor homogêneo, com pequena diversidade e qualidade de estudos sobre o tema, tem sua atuação, na verdade, heterogênea.

Neste sentido, Etzioni (1973), entende o terceiro setor como um setor alternativo separado e equilibrado do Estado e do Mercado, em que as próprias organizações de cunho filantrópico e social se reconheciam como setores separados. Se algo não é governado principalmente pela lógica do mercado nem por uma cadeia de comando burocrática, deve fazer parte do "terceiro" setor.

Ainda de acordo com o autor, o terceiro setor é uma maneira de reduzir o governo em todos os níveis e uma maneira de envolver o setor privado em questões de cunho social, sendo significativamente mais eficaz do que as deixando a cargo do Mercado. A primeira vê o terceiro setor como um setor discreto caracterizado por certas qualidades como a civilidade; já os teóricos europeus tendem a ter uma visão híbrida, que considera as organizações do setor essencialmente como misturas de outros tipos de organização, como privadas e públicas, tendo limitações à distribuição de lucros e buscando um benefício comunitário, incluindo organizações como empresas sociais e cooperativas (DEFOURNY; NYSSENS, 2010).

No primeiro setor, o Estado exerce, por meio de seus órgãos e entidades, suas múltiplas atividades inclusive as de cunho social. Já no segundo setor, têm-se as organizações privadas, que atuam em busca de resultados financeiros por meio da troca de bens e serviços em benefício de seus sócios e investidores. Por fim, no terceiro setor estão as organizações privadas sem fins lucrativos que, por essência, existem por conta da ineficiência do Estado e dos objetivos inerentes ao capitalismo seguido pelo Mercado.

De acordo com Olak e Nascimento (2006) complementam, afirmando que essas entidades, de cunho social, são denominadas genericamente das mais diversas formas, como terceiro setor, Entidades sem Fins Lucrativos, Organizações Filantrópicas, beneficentes e de caridade e Organizações Não Governamentais (ONG).

Podem ainda ser fundações, institutos, associações comunitárias, entidades assistenciais e filantrópicas estabelecidas com finalidade pública, criadas por pessoas com o ideal de oferecer melhoria para a sociedade; concentram-se principalmente em ações voltadas para as áreas de educação, saúde, cultura, serviço social, religião, defesa de direitos, meio ambiente e associações profissionais, com grande número de colaboradores não remunerado, embora se observe um processo crescente de profissionalização nas mesmas (PEREIRA et al. 2013).

A essência dessas entidades é, em seu objetivo maior, servir à sociedade como forma de apoio aos outros dois primeiros setores (MARQUES et al., 2015). As organizações desse segmento possuem aspectos estruturais e operacionais distintos, se comparados ao primeiro e ao segundo setor.

As organizações que compõem o terceiro setor assumem diversas configurações e, de certa forma, procuram resolver problemas que o Estado não consegue ou não tem interesse de atender. Entretanto, uma característica comum está relacionada ao seu objetivo, que não converge para obtenção de lucro, e sim para o reinvestimento em recursos para legitimar sua existência (TENÓRIO, 2005; BERNARDES; CASAGRANDE, 2017).

\subsection{Avaliação de Desempenho (AD) e o terceiro setor}

Com base na literatura, o termo desempenho é sujeito a inúmeras variações semânticas e conceituais, embora existam consensos em torno de uma definição. Segundo Melnyk et al. (2014), o uso de medidas para 
avaliar o desempenho permitem identificar os níveis de desempenho e a comparação entre os níveis desejados e os atingidos no momento da avaliação. Já Neely, Gregory e Platts (1995) afirmam que tais medidas contribuem para evidenciar a necessidade de intervenção e de direcionamento de esforços que possam gerar benefícios para a organização, sendo suporte ao processo decisório dos gestores.

Ao avaliar o desempenho torna-se possível que planos e ações sejam traçados baseados em informações, e qualifica a tomada de decisão, visto que quantificam a eficiência e eficácia de ações passadas, de tal forma a traduzir a estratégia em um conjunto de medidas de desempenho.

A multiplicidade de definições para avaliação de desempenho, fez com que Ensslin et al. (2010) propusessem a AD como um instrumento de apoio à decisão, capaz de construir conhecimento no tomador de decisão, a respeito do contexto específico que se propõe avaliar, com base nos valores, premissas e necessidades de avaliação do próprio gestor, por meio de atividades que identificam, organizam, mensuram ordinalmente e cardinalmente, integram e permitem visualizar o impacto das ações e seu gerenciamento.

No contexto de organizações do terceiro setor, para uma organização sem fins lucrativos, medir o "sucesso" é muito mais difícil. Os autores sugerem que o leitor imagine uma organização cuja missão é aliviar o sofrimento humano. Como medir o desempenho de uma organização que possui uma missão tão abstrata? E por quais critérios o sucesso deve ser medido? (SAWHIL; WILLIAMSON, 2001).

No entanto, um dos principais componentes desse novo modelo quando analisado sob as características das organizações sem fins lucrativos é que ele não conseguiu replicar a maneira com que as empresas privadas medem seu desempenho.

Moxham (2009) afirma que a questão de como avaliar o desempenho das organizações do terceiro setor é uma questão que precisa de atenção. Como nos setores privado e público, não há consenso na literatura quanto ao que os critérios devem ser usados. A autora aponta a existência de quatro direcionadores, a saber: (i) relatórios financeiros, para dar publicidade à aplicação dos recursos recebidos; (ii) demonstração das conquistas, para exteriorizar o impacto de suas ações; (iii) controle operacional; e (iv) facilitar a melhoria contínua.

Avaliar o desempenho das organizações do terceiro setor não deve ser diferente de avaliar o desempenho das organizações do setor privado ou público nestes aspectos. Portanto, a literatura dos setores supracitados pode ser usada para informar o design do modelo de avaliação do desempenho em organizações do terceiro setor.

\subsection{Abordagens utilizadas no Terceiro Setor}

Uma gama de ferramentas de medição de desempenho foi introduzida e utilizada pelas organizações do terceiro setor. Além dos quadros de medição específicos para organizações sem fins lucrativos, outros modelos originalmente desenvolvidos para os setores público e privado fazem referência explícita à sua aplicabilidade neste setor - por exemplo, Balanced Scorecard, de Kaplan e Norton (1992), o Modelo EFQM de Excelência, da British Quality Foundation (2002) e o Prism Performance, desenvolvido por Neely nos anos 2000.

As metodologias a seguir foram selecionadas a partir da literatura científica como aplicáveis a estas organizações. No entanto, não se deve tê-las como as únicas, mas sim como já testadas em organizações pertencentes a este setor e que fizeram parte do Portfólio Bruto utilizados nesta pesquisa.

Em relação às potencialidades das sete abordagens de avaliação de desempenho organizacional aplicadas no terceiro setor supracitadas, entende-se que a exposição destas permitirá a identificação dos pontos mais relevantes a serem levados em conta para a elaboração da proposta de framework de avaliação de desempenho para o terceiro setor que se propõe neste trabalho e foram organizados no Quadro 1:

Quadro 1 - Potencialidades e Aplicações no Terceiro Setor

\begin{tabular}{|l|l|}
\hline \multicolumn{1}{|c|}{ Abordagem } & \multicolumn{1}{c|}{ Potencialidades } \\
\hline $\begin{array}{l}\text { Social Return on Investment } \\
\text { (SROI) }\end{array}$ & $\begin{array}{l}\text { Ferramenta de medição criada para organizações do terceiro setor baseada } \\
\text { em resultados, relacionada à análise de custo-benefício para combinar }\end{array}$ \\
\hline
\end{tabular}




\begin{tabular}{|c|c|}
\hline & $\begin{array}{l}\text { benefícios monetizados da empresa, na forma de fluxos de caixa, com o fluxo } \\
\text { de benefícios sociais quantificados. }\end{array}$ \\
\hline Balanced Scorecard (BSC) & $\begin{array}{l}\text { O BSC fornece às organizações do terceiro setor um mecanismo para rastrear } \\
\text { o desempenho holisticamente por meio de informações quantitativas e } \\
\text { qualitativas. A abordagem ajuda a identificar os principais impulsionadores } \\
\text { ou formas de alcançar o sucesso a partir dessas perspectivas sociais e } \\
\text { financeiras. }\end{array}$ \\
\hline Benchmarking & $\begin{array}{l}\text { O benchmarking no terceiro setor pode ser utilizado para avaliar a captação } \\
\text { de recursos, as finanças e desempenho de RH. O objetivo não é pressão } \\
\text { competitiva, mas uma resposta aos pedidos de maior responsabilidade, } \\
\text { redução de custos, melhor qualidade, busca de novas ideias etc. }\end{array}$ \\
\hline Performance Prism & $\begin{array}{l}\text { O modelo fornece uma imagem equilibrada dos negócios destacando } \\
\text { medidas externas (partes interessadas) e internas (estratégia, processo e } \\
\text { capacidade), bem como integrando medidas financeiras e não financeiras. }\end{array}$ \\
\hline $\begin{array}{l}\text { European Foundation for } \\
\text { Quality Management } \\
\text { Excellence Model }\end{array}$ & $\begin{array}{l}\text { Trata-se de uma estrutura de autoavaliação que permite a mensuração dos } \\
\text { pontos fortes e de melhoria de uma organização em todas as suas atividades. } \\
\text { Fornece uma estrutura holística que aborda uma ampla gama de questões } \\
\text { organizacionais, inclusive as relacionadas à sociedade, e dá atenção aos } \\
\text { impactos por meio dos critérios de resultados. }\end{array}$ \\
\hline $\begin{array}{l}\text { Multidimensional and } \\
\text { Integrated Model of } \\
\text { Nonprofit Organizational } \\
\text { Effectiveness (MIMNOE) }\end{array}$ & $\begin{array}{l}\text { A principal potencialidade do MIMNOE deriva dos indicadores quantitativos } \\
\text { e qualitativos atribuídos à análise da eficácia da gestão das entidades e dos } \\
\text { programas por ela executados. }\end{array}$ \\
\hline $\begin{array}{ll}\text { Competing } & \text { Values } \\
\text { Framework (CVF) }\end{array}$ & $\begin{array}{l}\text { Fornece uma abordagem abrangente para identificar as atividades } \\
\text { gerenciais e fatores ambientais que influenciam a eficácia nas organizações. } \\
\text { Útil para ajudar na identificação dos pontos fortes, pontos fracos e } \\
\text { oportunidades de melhoria. }\end{array}$ \\
\hline
\end{tabular}

Fonte: Grabowski et al.(2015), Murray e Neitzert (2009), Manville e Broad (2013), Sowa e Selden (2004), Estrada, Sousa e Lopes (2017), Mcadam, Hazlett e Casey (2005), Petri (2005).

Apresentadas as potencialidades de cada uma das abordagens de avaliação de desempenho utilizadas no terceiro setor, passa-se, agora à apresentação dos procedimentos de pesquisa utilizados nesta pesquisa.

\section{MÉTODO E PROCEDIMENTOS DE PESQUISA}

De acordo com Raupp e Beuren (2006), o enquadramento de pesquisa norteia o investigador a buscar uma resposta para determinado problema e se divide conforme os objetivos, os procedimentos e abordagem do problema.

Quanto aos objetivos, Silva e Menezes (2005) afirmam que a pesquisa descritiva tem como principal objetivo a descrição das características de determinada população ou fenômeno, ou ainda, o estabelecimento de relações entre as variáveis. A pesquisa descritiva, usualmente, é considerada intermediária entre a pesquisa exploratória e a explicativa, ou seja, não é tão preliminar como a primeira nem tão arraigada quanto a segunda. Neste contexto, descrever significa identificar, relatar, comparar, entre outros aspectos (MACHADO et al., 2007).

Por suas características e objetivos, a presente pesquisa apresenta caráter descritivo, no momento em que ocorre a revisão da literatura, fazendo uma análise crítica do que já foi publicado sobre avaliação de desempenho em organizações do terceiro setor.

De acordo com Creswell (2007), a abordagem de pesquisa auxilia o pesquisador na definição das técnicas de investigação e são tipificadas como qualiquantitativa ou mista.

Este estudo apresenta características inerentes à abordagem qualitativa, com técnicas de teoria embasada na realidade, visto que se propõe a analisar e interpretar as ferramentas de avaliação de 
desempenho em organizações do terceiro setor preconizadas pelos artigos que compõem o Portfólio Bruto, com objetivo de propor um modelo composto por indicadores ideais para a avaliação de desempenho.

No que se refere à lógica a ser utilizada pela pesquisa é a dedutiva, pois se propõe a fazer a conexão descendente entre a teoria e a ocorrência dos fenômenos, ou seja, partindo dos referenciais teóricos e experiências de outros pesquisadores para a elaboração do modelo, contribuindo assim na validação da teoria (MARCONI; LATAKOS, 2008; MACHADO et al., 2007).

A estratégia de pesquisa envolve a escolha das técnicas de pesquisa para conduzir o estudo. Para Raupp e Beuren (2006), não há unanimidade na literatura sobre a tipologia e seus agrupamentos. Desta forma, sugerem os autores, o enquadramento deve ser realizado de acordo com a necessidade do pesquisador em relação ao estudo.

Esta pesquisa apresenta elementos de uma pesquisa bibliográfica, que é feita, de acordo com Fonseca (2002) e Gil (2002), a partir do levantamento de referências teóricas já analisadas, e publicadas, tais como livros e artigos científicos.

Quanto à coleta de dados, diante as inúmeras maneiras de coletar os dados para que seja possível realizar um estudo científico, em razão da realidade em que esta pesquisa está inserida, os dados foram coletados de fontes secundárias, ou seja, a partir de materiais já publicados e disponíveis para o pesquisador.

De acordo com Gerhardt e Silveira (2009), os resultados da pesquisa podem ser de características básica ou aplicada. A pesquisa básica objetiva gerar conhecimentos novos, úteis para o avanço da Ciência, sem aplicação prática prevista. Envolve verdades e interesses universais; a pesquisa aplicada busca gerar conhecimentos para aplicação prática, dirigidos à solução de problemas específicos. Envolve verdades e interesses locais.

Com base nessas definições e nas suas características e objetivos, como resultado de pesquisa este estudo é caracterizado como uma pesquisa aplicada.

\subsection{Procedimentos para a construção do modelo}

A utilização do Balanced Scorecard em organizações do terceiro setor depende da adaptação da abordagem, colocando a missão como mais relevante do que o desempenho financeiro. Tal procedimento possibilitará o atingimento dos objetivos estratégicos e pode ajudar as organizações a determinar com eficácia as medidas que permitirão avaliar o seu desempenho.

Por esta razão, o autor propôs o aperfeiçoamento do BSC, utilizando como ferramenta a Metodologia Multicritério de Apoio à Decisão - Construtivista e desenvolveu, para fins de análise, as seguintes etapas: (i) contextualização; (ii) estruturação; (iii) avaliação; (iv) efetividade e proatividade; (v) flexibilidade e operacionalidade. 
Figura 3 - Balanced Scorecard Aperfeiçoado

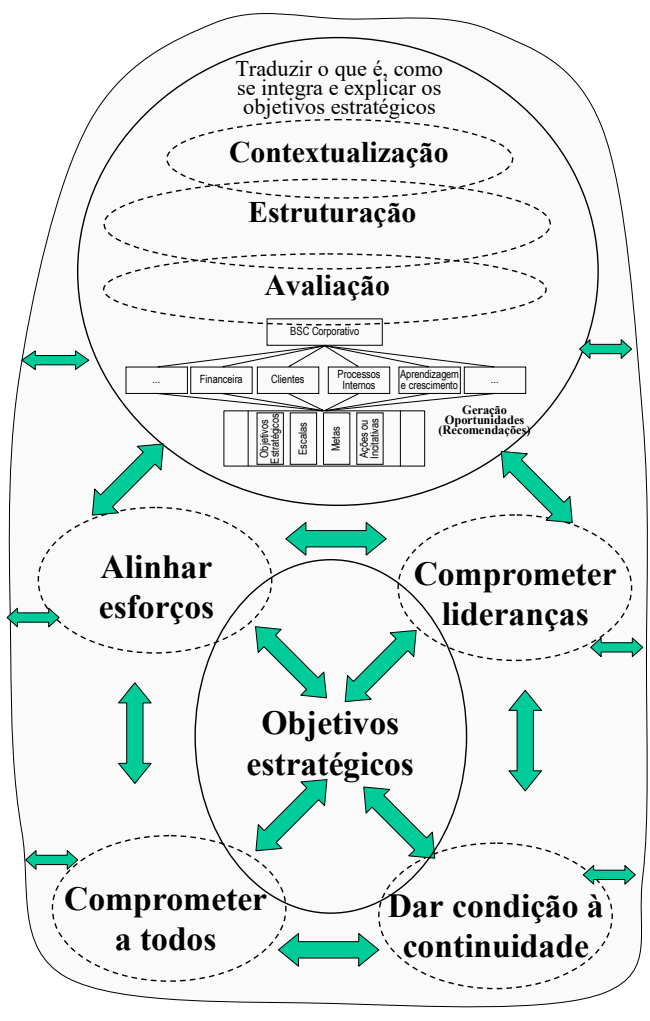

Fonte: Petri (2005 p.189)

Essa proposta de aperfeiçoamento do Balanced Scorecard de Petri (2005), chamada neste estudo de Balanced Scorecard Aperfeiçoado foi escolhida por apresentar com base em suas premissas, o aperfeiçoamento do processo de avaliação de desempenho nos aspectos mais citados como relevantes para os autores mencionados no capítulo anterior.

\section{RESULTADOS}

A proposta de framework foi estruturada com base no Balanced Scorecard Aperfeiçoado foi estabelecida em quatro fases da proposta, que são: (i) contextualização; (ii) estruturação; (iv) avaliação; e (v) propor aperfeiçoamentos, e foram baseadas nas características e funcionalidades (instrumentos) das sete abordagens - SROI, BSC, Benchmarking, EFQM, Performance Prism, MIMNOE e CVF, e bem como na abordagem de BSC Aprimorado de Petri (2005). A Figura 4 apresenta o design da proposta de frameworkque busca esclarecer as etapas e os autores que embasaram as escolhas para realização da presente proposta. 
Figura 4 - Design da Proposta de Framework

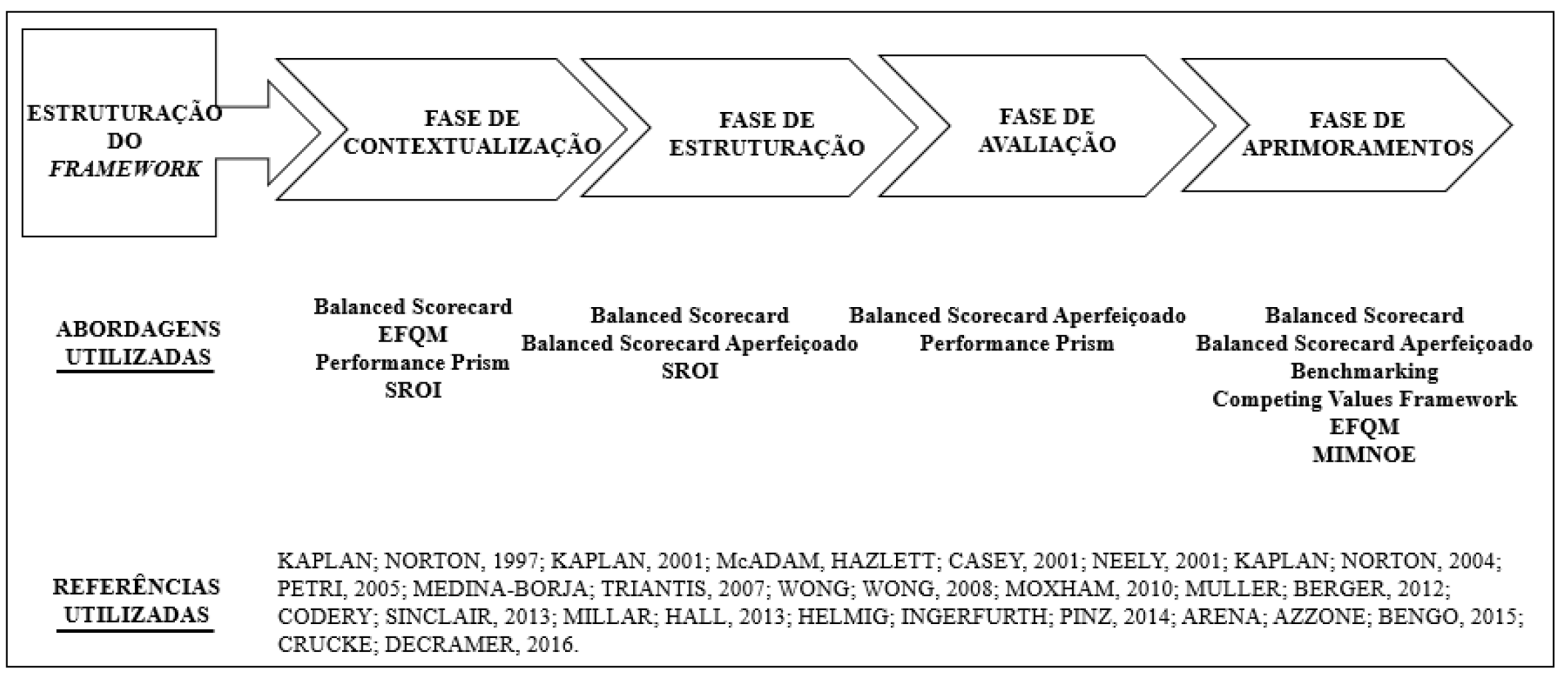

Fonte: Elaborado pelo autor (2018).

A fase de Contextualização consiste na identificação do ambiente, os envolvidos e seus relacionamentos, bem como os objetivos e desafios organizacionais coletados por meio de documentos, entrevistas e consultas a especialistas.

O estabelecimento da missão é a primeira etapa da fase de contextualização. Para o estabelecimento e ou fortalecimento da missão - fortalecer no sentido de dar divulgação e facilitar o entendimento por parte dos stakeholders - a pergunta que os gestores devem se fazer é: "Qual o objetivo de ser da entidade"?

A resposta para esta indagação consiste em definir o propósito da organização, deixando claro o segmento em que está inserida. Em organizações sem fins lucrativos que atuam no terceiro setor, a definição da missão pode e deve ter a participação das principais partes interessadas, incluindo os financiadores e os atingidos, para que haja clareza quanto ao escopo de atuação a forma com que será reconhecida pelos stakeholders.

Este entendimento coincide com a de Kaplan (2001). Para o autor, o início de qualquer sistemática de avaliação de desempenho organizacional deve ser uma declaração clara da missão da entidade. Sem isso, as medidas de desempenho se concentram em melhorias operacionais locais em vez de saber se a estratégia está sendo alcançada. 
Figura 5 - Fase de Contextualização

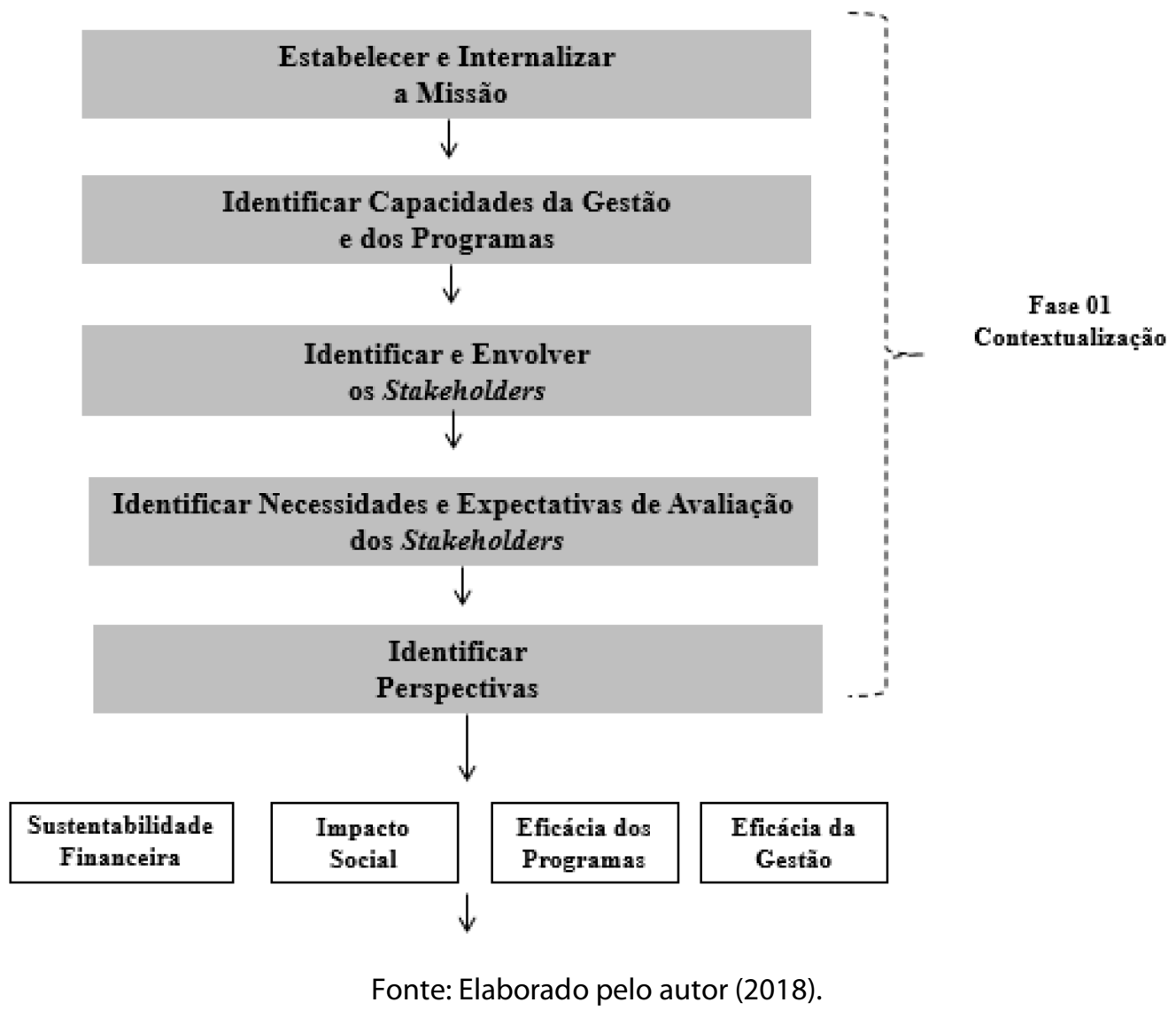

Na sequência, recomenda-se Identificar Capacidades, questionando-se "O que fazemos e como fazemos?". Inspirada na MIMNOE, esta etapa refere-se à definição da forma como a organização ou programa opera, identificando suas estruturas instaladas e os processos operacionais executados.

Quando aplicada na prática, esta identificação de estruturas se dá por meio do levantamento da capacidade de atendimento dos objetivos em termos de recursos humanos e de infraestrutura, bem como das fontes de recursos e a sustentabilidade financeira da entidade. Recomenda-se o envolvimento de equipe técnica (externa ou interna) para instrumentalizar os tomadores de decisão.

O envolvimento dos stakeholders, uma das premissas da abordagem SROI, é importante para que os gestores consigam garantir o engajamento dos stakeholders-chave. A gestão do envolvimento das partes interessadas se dá pela necessidade de recursos para a sustentabilidade e continuidade de suas atividades e corresponde a uma etapa vital do processo de AD.

Inicialmente, recomenda-se que os gestores identifiquem os tipos de stakeholders (interno e externo) e o grau de influência de cada um dos grupos de modo a verificar o grau de importância deles para a organização, bem como identificar o grau e priorização que deverá ser levado em conta na execução da missão e dos objetivos organizacionais.

Em seguida, tem-se a identificação das necessidades e expectativas de avaliação do stakeholders. quais suas aspirações, seus medos e suas expectativas em relação à entidade de modo a agregar suas percepções e contribuições para o desenvolvimento das métricas de avaliação. Este levantamento pode ocorrer por meio de entrevista utilizando-se como instrumento de coleta de dados um questionário.

Em relação à definição das dimensões avaliadas, denominadas por Kaplan e Norton (1992) como perspectivas - identificar perspectivas, as organizações sem fins lucrativos devem desenvolvê-las a partir da missão, das capacidades de gestão e dos programas e das necessidades e expectativas de avaliação dos stakeholders. 
A partir da literatura estudada, recomenda-se a utilização de pelo menos quatro perspectivas que abranjam aspectos econômico-financeiros, dos stakeholders, de eficiência na gestão; impacto social; aprendizado e crescimento; processos internos; e eficiência dos programas (KAPLAN, 2001; MEDINA-BORJA; TRIANTIS, 2007; HELMIG; INGERFURTH; PINZ, 2014; ARENA; AZZONE; BENGO, 2015; CRUCKE; DECRAMER, 2016).

A segunda fase, de Estruturação - Figura 6, objetiva identificar especificamente o que é relevante no contexto decisório e tem início com elaborar os objetivos estratégicos. Os objetivos estratégicos, correspondem as metas amplas que a empresa pretende atingir, que devem estar diretamente relacionadas à missão da organização e servem para nortear a definição dos objetivos táticos e operacionais.

Tais objetivos representam a tradução da estratégia em termos operacionais a partir da missão e das perspectivas (ou dimensões) escolhidas, sendo imprescindível que sejam mensuráveis e controláveis.

A definição dos objetivos pode ser facilitada com as seguintes perguntas para reflexão a serem respondidas pelos tomadores de decisão com base na fase de contextualização: "o que devemos fazer para atingir nossos objetivos"? "onde se deve chegar ao atingir nossos objetivos?"; "quando atingir nossos objetivos?"; "quem deve se beneficiar ao se atingir nossos objetivos?"; "como se chega ao consenso quanto aos nossos objetivos?".

Figura 6 - Fase de Estruturação

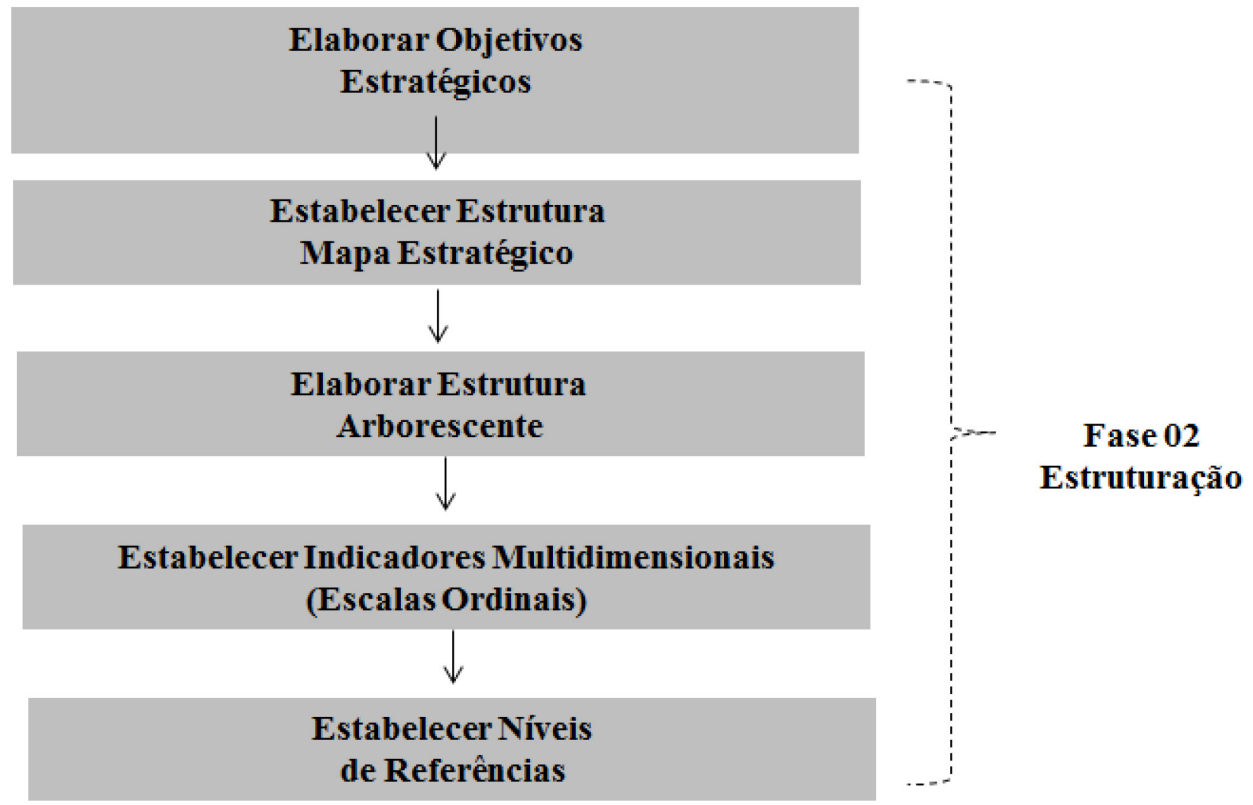

Fonte: Elaborado pelo Autor (2018).

Em seguida, tem-se a etapa de estabelecer do mapa estratégico, que descreve a lógica da estratégia para toda a organização. A Figura 7 apresenta, com base em Kaplan (2001), o modelo de mapa adotado por organizações do terceiro setor.

O mapa estratégico demonstra como as estratégias ligam-se aos processos organizacionais, permitindo o alinhamento dos esforços de todos os colaboradores à estratégia organizacional. 0 entendimento sobre a ligação e alinhamento entre os processos é requisito básico para a implantação deste modelo proposto em organizações sem fins lucrativos que atuam no terceiro setor, pois é a partir desta integração que residem os caminhos para o cumprimento da razão social da organização (PETRI, 2005).

Em seguida, a elaboração de estrutura arborescente, baseia-se no entendimento de Brunswik (1956), que afirma que os seres humanos organizam mais facilmente os aspectos cotidianos em forma de árvore Figura 8, ou seja, em uma estrutura explicativa. 
Figura 7 - Mapa Estratégico para Organizações do Terceiro Setor

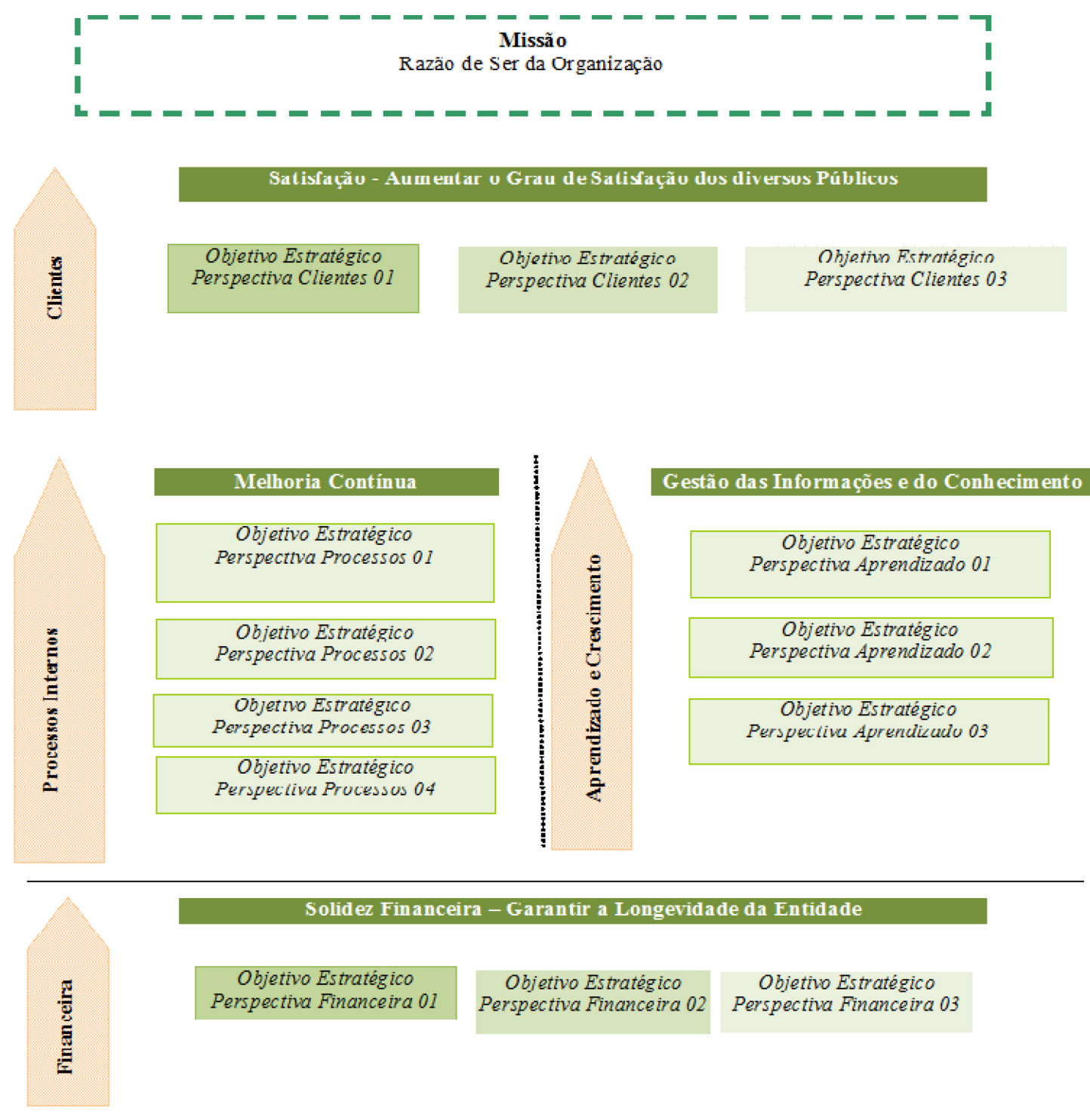

Fonte: Adaptado de Kaplan (2001).

As estruturas arborescentes fazem uso da lógica de decomposição, na qual critérios de difícil mensuração são decompostos em subcritérios, facilitando o processo e construindo hierarquia entre os objetivos estratégicos e identificando áreas de preocupação percebidas pelos stakeholders como necessárias para a gestão do contexto em estudo (ENSSLIN; MONTIBELLER; NORONHA,2001; DEZEM, 2015).

Depois de ter a estrutura arborescente, também chamada de estrutura hierárquica de valor, recomenda-se a construção das escalas ordinais, que correspondem aos indicadores, que podem ser qualitativas (desejos, sentimentos, motivações) ou quantitativas (numérica) e apenas preferencialmente ordenadas (PETRI, 2005; ENSSLIN, 2010). 
Figura 9 - Framework de Estrutura Arborescente

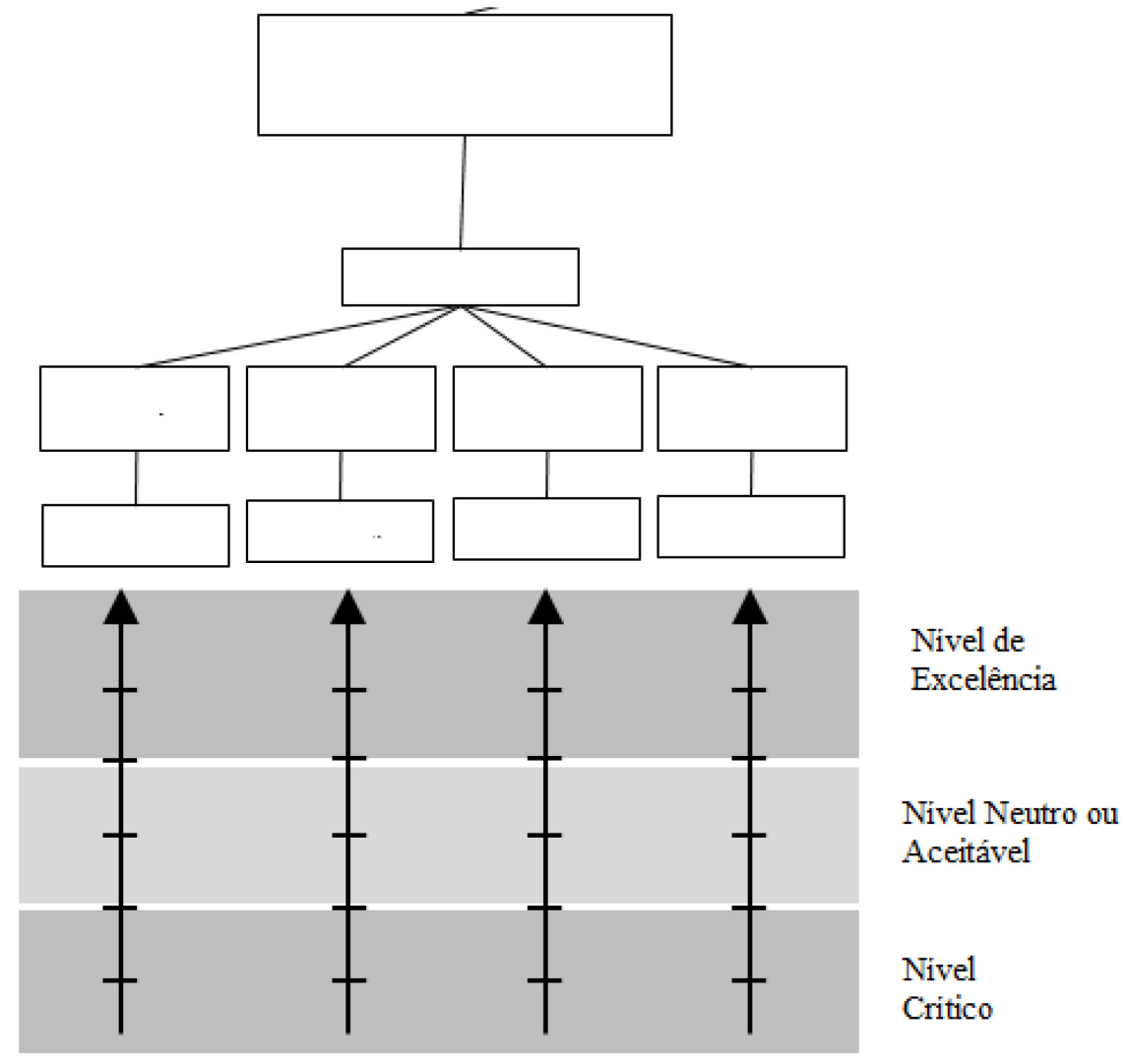

Fonte: Adaptado de Dezem (2015).

O estabelecimento de indicadores multidimensionais em organizações do terceiro setor não difere de outros tipos de entidade - por derivarem da missão, dos objetivos estratégicos etc., e reportam-se às escalas ordinais, fazendo uso de números absolutos, relações percentuais, índices, dentre outros, como, por exemplo, o grau de satisfação de um estudante que tenha participado de um projeto educacional e a relação alunos certificados / atendimentos brutos da mesma entidade utilizando relações percentuais em ambas métricas.

Em seguida, recomenda-se estabelecer os níveis de referência, que, de acordo com Petri (2005) apontam em que nível as escalas são equivalentes. Cabe ressaltar que estes níveis têm a mesma igualdade de preferência em todos os indicadores e contribuem para a determinação das taxas de compensação e para a integração do modelo.

Recomenda-se a utilização de níveis "de excelência" para representar o resultado "neutro ou aceitável" para os resultados atingidos dentro das expectativas (ou metas) pré-estabelecidas e "crítico" nos casos em que os resultados estão abaixo do esperado pela organização.

Em suma, os processos envolvendo os indicadores são mensurados de modo a permitir a análise da situação atual, onde para os aspectos que se encontram em desempenho "crítico" possam originar ações de aperfeiçoamento dos objetivos e níveis de referência desejados no modelo de avaliação.

A fase seguinte, de Avaliação, consiste em refinar as informações construídas/coletadas nas fases anteriores e identificar o quanto as ações, decorrentes dos objetivos estratégicos traçados, contribuem ou prejudicam o desempenho global (PETRI, 2005). A Figura 9 apresenta as etapas desta fase.

A fase de avaliação tem como principal finalidade a transformação de escalas ordinais em cardinais, que, de acordo com Dezem (2015), ocorre pelo método MACBETH desenvolvido por Bana e Costa em 1995, uma vez que possui respaldo teórico, representatividade, confiabilidade e reconhecimento prático. Com a ajuda do software de mesmo nome, constroem-se escalas cardinais, denominam-se Funções de Valor, que 
atendam os critérios de avaliação estabelecidos nas duas etapas anteriores (LACERDA; ENSSLIN; ENSSLIN, 2011).

A etapa seguinte corresponde ao estabelecimento das taxas de substituição, que devem informar a diferença de atratividade entre os níveis de referência dos indicadores. Após a obtenção das taxas de cada critério, Bortoluzzi et al. (2009) afirmam ser possível transformar o valor da avaliação de cada objetivo estratégico em valores de uma avaliação global. Em suma, as taxas de compensação consistem em expressar a contribuição de um objetivo estratégico para o objetivo superior ao passar de um nível para outro.

Com os indicadores (as escalas ordinais), as funções de valor (escalas cardinais) e as taxas de compensação ou contribuição pode-se apurar o desempenho da organização, chamado por Petri (2005) de avaliação global, que permite a identificação do desempenho atual da organização.

Importante salientar que na etapa de apurar o desempenho, é necessária a realização da avaliação global a partir da equação de agregação aditiva, que determina a soma dos valores parciais obtidos pelo desempenho atual em cada critério, ponderada pelas taxas de substituição, sendo apresentadas a seguir (ENSSLIN; MONTIBELLER; NORONHA, 2001, p. 244):

$\mathrm{V}(\mathrm{a})=\mathrm{w} 1 . \mathrm{v} 1(\mathrm{a})+\mathrm{w} 2 \cdot \mathrm{v} 2(\mathrm{a})+\mathrm{w} 3 \cdot \mathrm{v} 3(\mathrm{a})+\ldots+\mathrm{wn} \cdot \mathrm{vn}(\mathrm{a})$

Onde:

V (a) = valor global do status quo; onde "a" representa o Status Quo,

v1 (a), v2 (a), ... vn (a) = valor parcial nos critérios $1,2, \ldots, \mathrm{n}$;

$\mathrm{w} 1, \mathrm{w} 2, \ldots \mathrm{wn}=$ taxas de substituição nos critérios $1,2, \ldots, \mathrm{n}=$ número de critérios.

Em seguida, na etapa de estabelecer as relações causa-efeito, faz-se a verificação das ações e seus impactos, ou seja, a relação causa-efeito e se a organização atinge ou não seus objetivos e sua missão organizacional.

Figura 9 - Fase de Avaliação

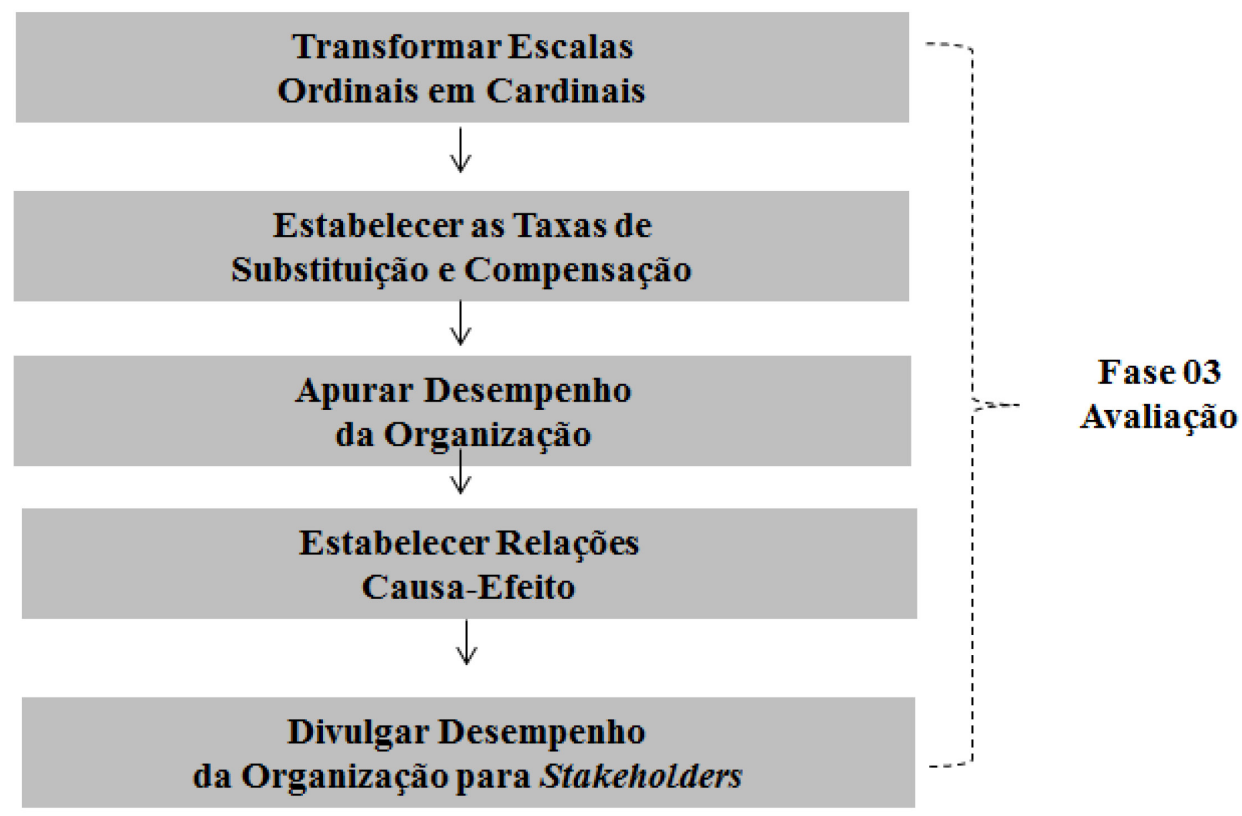

Fonte: Elaborado pelo Autor (2018)

A última etapa da fase de avaliação corresponde a divulgar o desempenho da organização para os stakeholders. Tal procedimento é parte importante da etapa "envolver os stakeholders", descrita na fase de contextualização. As partes interessadas, que contribuíram para o desenvolvimento do modelo, aguardam as informações provenientes da medição executada para que possam, assim, tomar decisões (como a de doar ou 
não recursos) e realizar a avaliação e, dependendo do grau de envolvimento com a organização do terceiro setor, a gestão do desempenho.

Esta divulgação pode se dar por meio de relatório físico ou digital, disponibilizado em formato físico ou digital, conforme interesse e capacidades da organização sem fins lucrativos.

$\mathrm{Na}$ última fase - Figura 10, são elaboradas estratégias que possibilitem melhorar o desempenho da organização do terceiro setor, por meio do conhecimento gerado na fase de avaliação, onde cada critério possui uma performance "excelente", "normal" ou "crítica". Bortoluzzi et al. (2009) afirma que é por meio deste conhecimento adicional que é possível identificar ações de melhorias.

Ensslin et al. (2010), destacam que esta etapa permite identificar onde é conveniente atuar, o processo para gerar ações que promovam o aperfeiçoamento do desempenho global, e visualizar as consequências da implementação em nível local ou operacional, no nível tático e estratégico.

Tem-se início com a comparação do desempenho. De forma a analisar se o desempenho atual da organização está de acordo com os resultados obtidos por organizações pertinentes - entidades que possuem o mesmo objetivo ou ramo de atuação, a comparação dos resultados é recomendada pelas abordagens benchmarking e o Modelo de Excelência da EFQM e deve ser executada com a comparação com outra entidade do mesmo setor, mesma atuação social ou que tenha similaridades possíveis de comparação e que, principalmente, sejam referências em suas áreas de atuação.

$\mathrm{Na}$ sequência, tem-se que propor aprimoramentos, que congrega os prismas dos objetivos estratégicos, da satisfação dos stakeholders, das escalas e níveis de referência, dos indicadores estabelecidos e dos processos executados. Recomenda-se, assim como na etapa de contextualização e estruturação, a participação dos stakeholders relevantes no processo.

A partir disto, recomenda-se elaborar novo mapa estratégico, agregando os novos objetivos, alterando escalas, níveis e indicadores, se for o caso, assim como a inclusão de novas práticas de processos de gestão.

Como todo ciclo "PDCA" - Plan, Do, Check and Act, esta proposta de modelo de avalição do desempenho deve incorporar os feedbacks coletados durante as fases anteriores de forma a garantir o aprendizado, a inovação e a evolução da forma de avaliar a organização e melhorar sua gestão.

Em seguida, deve-se realizar o novo alinhamento com a missão organizacional, agregando os aperfeiçoamentos propostos apresentados no novo mapa para, na sequência, fomentar o desenvolvimento de novas capacidades e tornar o a prática de avaliar e gerir o desempenho um processo contínuo e, por fim, mobilizar mudanças, etapa que deve ser executada pela liderança da organização, tal qual recomendado por Kaplan e Norton (2000) e Petri (2005). 
Figura 10 - Fase de Propor Aperfeiçoamentos

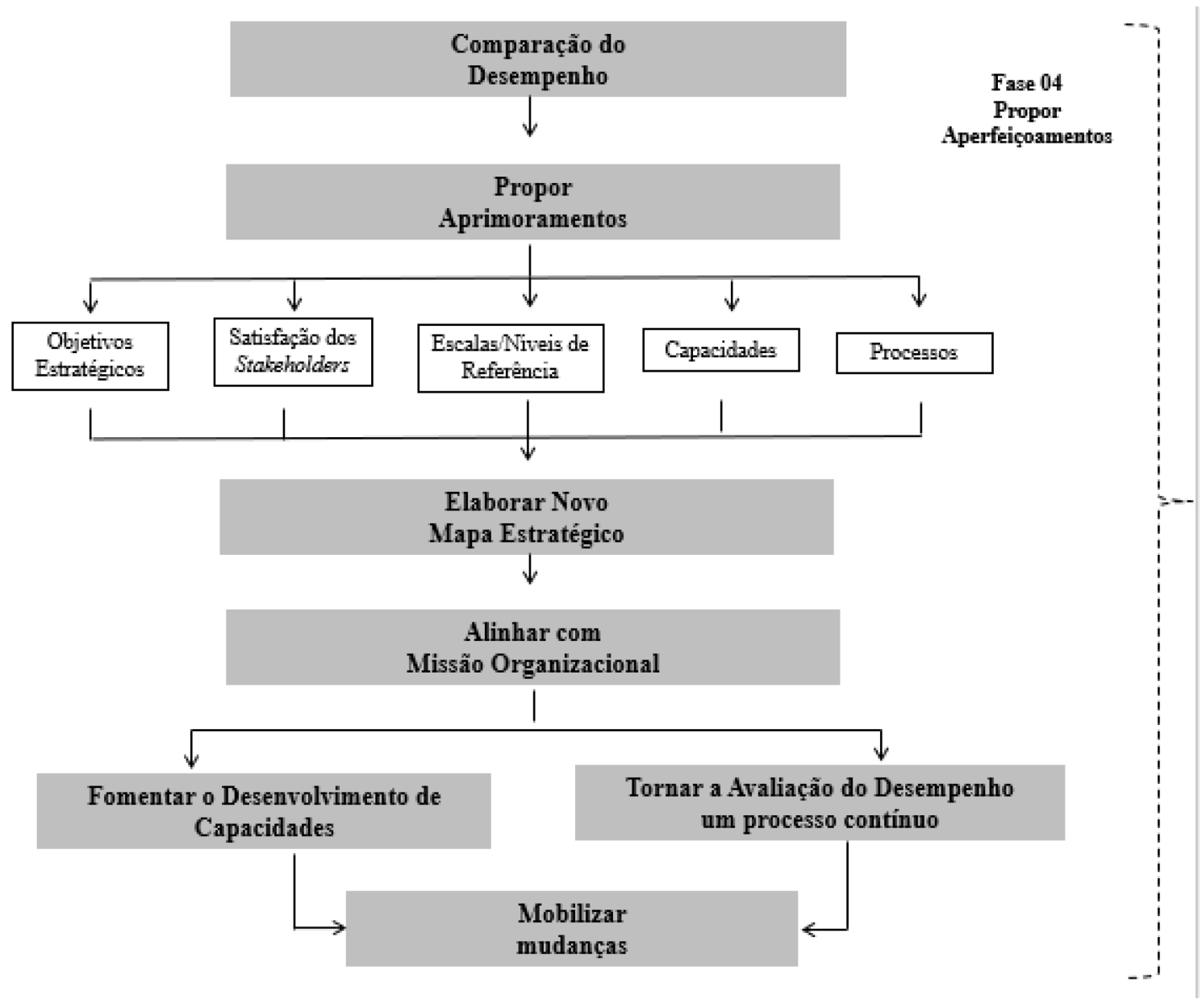

Fonte: Elaborado pelo autor (2018).

Em suma, o produto esperado desta fase de propor aprimoramentos é a definição de estratégias, objetivos táticos e operacionais, desdobrados em planos de ação para cada objetivo operacional, especificando as metas a serem cumpridas, os responsáveis pela execução e as datas para conclusão com vistas a melhorar o desempenho da organização no próximo ciclo. A Figura 11 apresenta o arquétipo da proposta de modelo.

Assim como no framework do Competing Values Framework (CVF) - Estrutura de Valores Concorrentes, a fase de contextualização, localizada no quadrante superior esquerdo, depende da colaboração entre os envolvidos, em que a organização "olha para si", para suas capacidades e tem foco no desenvolvimento de longo prazo. A fase de estruturação, no quadrante superior direito, tem a conotação de criação, visto o estabelecimento de elementos fundamentais para o desenvolvimento do modelo, como os objetivos estratégicos, os indicadores multidimensionais, a estrutura arborescente e os níveis de referência. 
Figura 11 - Proposta de Modelo Estruturado

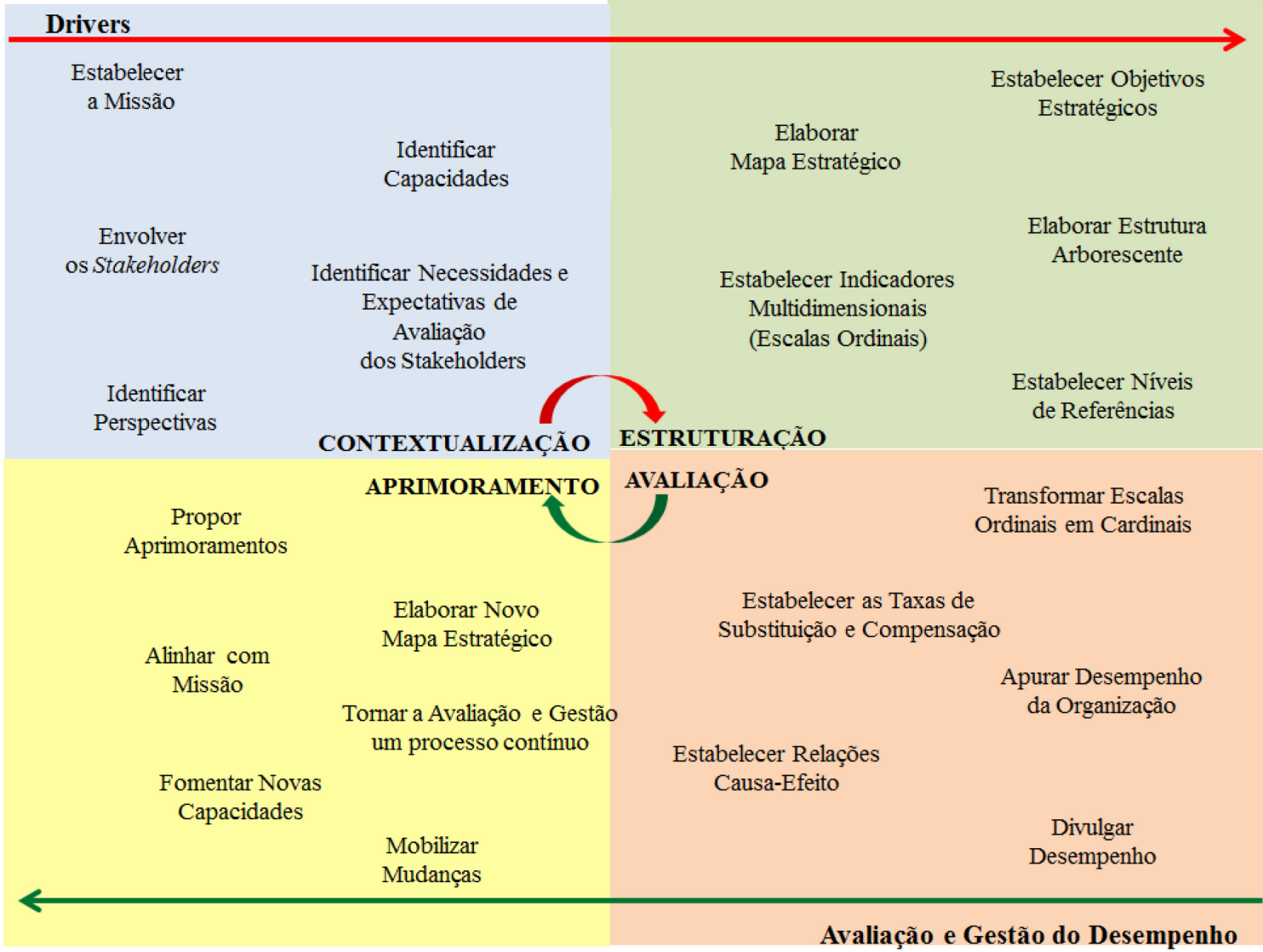

Fonte: Elaborado pelo Autor (2018).

Nos quadrantes interiores, tem-se a fase de avaliação, na direita, com foco na performance e da divulgação do grau de competitividade atual - status quo da organização e, no canto esquerdo, a fase de aprimoramento, em que aspectos de controle e evolução buscam ser identificadas com a revisão dos elementos nas fases anteriores e no feedback dos stakeholders.

\section{CONCLUSÃo}

Com base na bibliografia apresentada, selecionada a partir das premissas do autor desta pesquisa, percebeu-se a existência de entidades do terceiro setor que adotam metodologias para avaliar o desempenho embasados na lógica comercial e concorrencial de forma arbitrária, sem nem mesmo entender as premissas e diretrizes do mesmo. Estes modelos, focados apenas em medidas financeiras, não conseguem promover a integração entre estas medidas e outras não financeiras ou, se o fazem, não abarcam a integração das variáveis com a missão organizacional, não sendo, portanto, suficientes para avaliar o cumprimento dos objetivos.

Para remediar esta lacuna, abordagens ou metodologias tentam integrar diferentes medidas de desempenho relevantes, com múltiplas dimensões e que busquem a interação entre a missão e as medidas de desempenho.

Com base em seus objetivos e características, em especial de fornecer um quadro integrado de avaliação de desempenho, que envolve aspectos financeiros e não financeiros, o BSC, na sua versão aperfeiçoada proposta por Petri (2005), foi a metodologia escolhida para a proposta de frameworkpara avaliar as organizações do terceiro setor. 
Entende-se que o problema de pesquisa - Qual as etapas para a construção de ima proposta de framework para avaliar o desempenho de organizações do terceiro setor? foi solucionado a partir da proposta de frameworkapresentada na seção 4.

Essa estrutura integra outras abordagens apresentadas na literatura e contém quatro fases estruturadas, ou seja, a contextualização, fundamental para o levantamento de uma série de informações como as necessidades e expectativas dos stakeholders e estabelecimento da missão; a estruturação, momento que se estabelecem os objetivos estratégicos, a estrutura arborescente, os indicadores e níveis de referência; a avaliação, onde são transformadas as escalas ordinais em cardinais, o estabelecimento das taxas de compensação e a apuração do desempenho; por fim, a tem-se fase de propor aprimoramentos, em que há a revisão dos elementos estratégicos e a permite a ação focada nos pontos críticos apontados na fase anterior.

O objetivo geral foi atendido por meio da construção de uma proposta de estruturação de BSC para organizações do terceiro setor, elaborada a partir dos das metodologias citadas e/ou recomendadas nos artigos que compõem o Portfólio Bibliográfico, utilizadas por organizações de mesma finalidade no país e no mundo, como o Performance Prism, o Modelo de Excelência da EFQM, a Modelo Multidimensional e Integrado de Organizações sem Fins Lucrativos (MIMNOE), o Retorno Social sobre o Investimento(SROI), o Benchmarking, e a Estrutura de Valores Concorrentes.

Cabe ressaltar que a proposta de frameworkapresentada buscou integrar a missão, os stakeholderse estratégias com os elementos de avaliação do desempenho organizacional no terceiro setor. Por isso, recomenda-se adaptação de acordo com os objetivos de cada entidade.

A estruturação proposta nesta pesquisa se baseou nos autores que demonstram que medidas elaboradas em uma escala cardinal, a partir dos pontos de vista dos tomadores de decisão, apresentam a diferença de atratividade de um nível para outro na escala, possibilitando identificar o desempenho da organização do terceiro setor

Outro ponto relevante é que a proposição pode levar os tomadores de decisão a entender melhor o que está ocorrendo em uma organização (fase de contextualização). Ao explorar a operação de qualquer organização, é salutar ter atenção à estrutura e aos processos em vigor quanto ao grau em que estes processos e estruturas estão realmente operando no nível pretendido.

Por fim, cabe destacar que este trabalho apresenta uma proposta de estrutura para aplicar e operacionalizar o desempenho organizacional em vários arranjos organizacionais do terceiro setor. Espera-se ter proporcionado uma contribuição útil para o desafio contínuo de avaliar o desempenho de organizações sem fins lucrativos e para o aumento das discussões e aprofundamento do estudo e pesquisa do desempenho organizacional.

O desenvolvimento deste estudo estimula a exploração de alguns assuntos que não puderam ser desenvolvidos e aprofundados nesta pesquisa. Desta forma, recomendam-se os seguintes temas para trabalhos futuros: aplicar a proposta apresentada em entidades sem fins lucrativos, a fim de testar a validade necessária deste estudo teórico e desenvolver um estudo que relacione as dificuldades, desafios e oportunidades dos gestores em aplicar a proposta de modelo em questão em organizações do terceiro setor.

\section{REFERÊNCIAS}

ARENA, Marika; AZZONE, Giovanni; BENGO, Irene. Performance measurement for social enterprises. VOLUNTAS: International Journal of Voluntary and Nonprofit Organizations, v. 26, n. 2, p. 649-672, 2015.

BERNARDES, Leandro dos Santos; CASAGRANDE, Jacir Leonir. Terceiro Setor: O Processo de Formulação de Estratégias em uma Associação de Profissionais de Santa Catarina. Revista Borges, v. 7, n. 2, p. 82-108, 2017.

BORTOLUZZI, S.C. et al. Proposta de um modelo multicritério de avaliação de desempenho econômicofinanceiro para apoiar decisões de investimentos em empresas de capital aberto. CAP Accounting and Management, v. 3, p. 100-110, 2009. 
BRUNSWIK, Egon. Perception and the representative design of psychological experiments. California: Univ of California Press, 1956.

CRESWELL, J. W. Projeto de Pesquisa: Métodos Qualitativo, Quantitativo e Misto. 2. ed. Porto Alegre: Editora Artmed, 2007.

CRUCKE, Saskia; DECRAMER, Adelien. The development of a measurement instrument for the organizational performance of social enterprises. Sustainability, v. 8, n. 2, p. 161, 2016.

DEFOURNY, J; NYSSENS, M. Conceptions of social enterprise and social entrepreneurship in Europe and the United States: convergences and divergences. Journal of Social Entrepreneurship. v. 1, n. 1, p. 32-53, 2010.

DEZEM, V.Modelo Construtivista para Apoiar a Gestão: O Caso do Processo de Atendimento e Negócios de uma Agência Bancária. Dissertação (Mestrado em Administração) - Universidade do Sul de Santa Catarina, Florianópolis, 2015.

ENSSLIN, Leonardo et al. Avaliação do desempenho de empresas terceirizadas com o uso da metodologia multicritério de apoio à decisão-construtivista. Pesquisa Operacional, v. 30, p. 125-152, 2010.

ENSSLIN, L.; MONTIBELLER, G.; NORONHA, S. M. Apoio à Decisão: metodologia para estruturação de problemas e avaliação multicritério de alternativas. Florianópolis: Insular, 2001.

ESTRADA, Rui; SOUSA, Sérgio; LOPES, Ana Isabel Loureiro. Performance assessment system development based on performance prism in social services. Ir. INTERNATIONAL CONFERENCE ON INDUSTRIAL ENGINEERING AND ENGINEERING MANAGEMENT (IEEEM), Singapore, 2017. Proceedings [...]. Singapore: IEEE, 2017.

ETZIONI, Amitai. The third sector and domestic missions. Public Administration Review, v. 33, n. 4, p. 314 $323,1973$.

FONSECA, J. J. S. Metodologia da pesquisa científica. Fortaleza: Universidade Estadual do Ceará (UEC), 2002.

GRABOWSKI, L. et al. Competing values framework application to organizational effectiveness in voluntary organizations: A case study. Nonprofit and Voluntary Sector Quarterly, v. 44, n. 5, p. 908-923, 2015.

GERHARDT, Tatiana Engel; SILVEIRA, Denise Tolfo. Métodos de Pesquisa. Porto Alegre: Ed. URFRGS, 2009.

GIL, Antonio Carlos. Como elaborar projetos de pesquisa. 4. ed. São Paulo: Atlas, 2002.

HELMIG, Bernd; INGERFURTH, Stefan; PINZ, Alexander. Success and failure of nonprofit organizations: Theoretical foundations, empirical evidence, and future research. Voluntas: International Journal of Voluntary and Nonprofit Organizations, v. 25, n. 6, p. 1509-1538, 2014.

KAPLAN, R. S.; NORTON, D. P. The Balanced Scorecard: measures that drive performance. Harvard Business Review, v. 70, n. 1, p. 71-80, Jan./Feb. 1992.

KAPLAN, Robert S. Strategic performance measurement and management in nonprofit organizations. Nonprofit management and Leadership, v. 11, n. 3, p. 353-370, 2001.

KAPLAN, Robert S.; NORTON, David P. Organização Orientada para a Estratégia: Como as empresas que adotaram o Balanced Scorecard prosperam no novo ambiente de negócios. Rio de Janeiro: Elsevier, 2000.

LACERDA, R. T. O.; ENSSLIN, L.; ENSSLIN, S. R. A Performance Measurement Framework in Portfolio Management: A Constructivist Case. Management Decision, v. 49, p. 1-15, 2011. 
LEBARCKY, F. V.; FERNANDES, A. R.; MENDES, A. C. A.; SILVEIRA, T. S.. O Balanced Scorecard como ferramenta de avaliação de desempenho organizacional no Terceiro Setor. In: CONGRESSO USP DE CONTROLADORIA E CONTABILIDADE, 7., 2010, São Paulo. Anais [...]. Saõ Paulo: USP, 2010.

LINDGREN, Lena. The Non-profit Sector Meets the Performance-management Movement: A programmetheory approach. Evaluation, v. 7, n. 3, p. 285-303, 2001.

LIMA, C. R. M.; SOARES, T. C.; LIMA, M. A. Balanced Scorecard em Instituições de Ensino Superior: uma análise das perspectivas. Revista Eletrônica de Estratégia \& Negócios, v. 4, n. 1, p. 183-205, 2011.

MACHADO, D. G. et al. A Abordagem Metodológica Utilizada no Âmbito da Pesquisa Científica na Área da Ciência Contábil: estudo exploratório da Convenção de Contabilidade CRC/RS - 2005. In: CONVENÇÃO DE CONTABILIDADE DO RIO GRANDE DO SUL, 11., 2007, Bento Gonçalves. Anais [...]. Bento Gonçalves, CRC/SC, 2007. v. 1.p. 1-15

MACHADO, M. A. V. et al. O Balanced Scorecard em Entidades sem Fins Lucrativos: um Estudo De Caso. Revista de Informação Contábil (UFPE), v. 7, p. 35-54, 2013.

MANVILLE, Graham; BROAD, Martin. Changing times for charities: performance management in a third sector housing association. Public Management Review, v. 15, n. 7, p. 992-1010, 2013.

MARCONI, Marina de Andrade; LAKATOS, Eva Maria. Metodologia Científica. 5. ed. São Paulo: Ed. Atlas, 2008.

MARQUES, B. A.; et al. Terceiro Setor: panorama das tendências de 1998 a 2013 por meio de um estudo bibliométrico. Enfoque Reflexão Contábil, v. 34, n. 2, p. 71-89, 2015.

MCADAM, Rodney; HAZLETT, Shirley-Ann; CASEY, Christine. Performance management in the UK public sector: addressing multiple stakeholder complexity. International Journal of Public Sector Management, v. 18, n. 3, p. 256-273, 2005.

MEDINA-BORJA, Alexandra; TRIANTIS, Konstantinos. A conceptual framework to evaluate performance of non-profit social service organisations. International Journal of Technology Management, v. 37, n. 1-2, p. 147-161, 2007.

MELNYK, Steven A. et al. Is performance measurement and management fit for the future? Management Accounting Research, v. 25, n. 2, p. 173-186, 2014.

MILLAR, Ross; HALL, Kelly. Social return on investment (SROI) and performance measurement: The opportunities and barriers for social enterprises in health and social care. Public Management Review, v. 15, n. 6, p. 923-941, 2013.

MOXHAM, Claire. Performance measurement: Examining the applicability of the existing body of knowledge to nonprofit organisations. International Journal of Operations \& Production Management, v. 29, n. 7, p. 740-763, 2009.

MOXHAM, Claire; BOADEN, Ruth. The impact of performance measurement in the voluntary sector: Identification of contextual and processual factors. International journal of operations \& production management, v. 27, n. 8, p. 826-845, 2007.

MURRAY, Richard; NEITZERT, Eva. Tools for You: Approaches to proving and improving for charities, voluntary organisations and social enterprise.London:New Economics Foundation, 2009.

NEELY, A.; GREGORY, M.; PLATTS, K. Performance measurement system design: a literature review and research agenda. International journal of operations \& production management, v.15 n.4, p. 80-116, 1995. 
OLAK, P. A.; NASCIMENTO, D. T. Contabilidade para Entidades Sem Fins Lucrativos (Terceiro Setor). São Paulo: Atlas, 2006.

PAULA, Cleberson Luiz Santos de; BRASIL, Haroldo Guimarães; MÁRIO, Poueri do Carmo. Mensuração do Retorno Social de Organizações sem Fins Lucrativos por meio do SROI-Social Return On Investiment. Contabilidade Vista \& Revista, v. 20, n. 3, pp 127-155, 2009.

PEREIRA, R. S.; et al. Especificidades da gestão no terceiro setor. Revista Organizações em Contexto, v. 9, n. 18, p. 167-195, 2013.

PETRI, S.M. Modelo para apoiar a avaliação das abordagens de gestão de desempenho e sugerir aperfeiçoamentos: sob a ótica construtivista. Tese (Doutorado em Engenharia da Produção) Universidade Federal de Santa Catarina, Florianópolis, 2005.

QUINTAIROS, Paulo César Ribeiro et al. Aplicação do Balanced Scorecard a uma organização do terceiro setor. Revista Contabilidade e Controladoria, v. 1, n. 2, 2009.

RAUPP, F. M.; BEUREN, I. M. Metodologia da pesquisa aplicável às ciências sociais. In:BEUREN, I.M. (org.). Como elaborar trabalhos monográficos em contabilidade: teoria e prática. 3.ed. São Paulo: Atlas, 2006. p.76-97

ROSA, M. M. et al. O Balanced Scorecard em Organizações sem Fins Econômicos: um estudo de caso. Revista Eletrônica de Estratégia \& Negócios, v. 9, n. 1, p. 204-231, 2016.

SAWHILL, John C.; WILLIAMSON, David. Mission impossible?: Measuring success in nonprofit organizations. Nonprofit management and leadership, v. 11, n. 3, p. 371-386, 2001.

SELDEN, Sally Coleman; SOWA, Jessica E. Testing a multi-dimensional model of organizational performance: Prospects and problems. Journal of Public Administration Research and Theory, v. 14, n. 3, p. 395-416, 2004.

SILVA, Edna Lúcia da.; MENEZES, Estera Muszkat. Metodologia da pesquisa e elaboração de dissertação. 4. ed. Florianópolis: Ed. UFSC, 2005.

SMITH, Miriam. Diversity and Identity in the Non-profit Sector: Lessons from LGBT Organizing in Toronto. Social Policy \& Administration, v. 39, n. 5, p. 463-480, 2005.

SOWA, Jessica E.; SELDEN, Sally Coleman; SANDFORT, Jodi R. No longer unmeasurable? A multidimensional integrated model of nonprofit organizational effectiveness. Nonprofit and voluntary sector quarterly, $\mathrm{v}$. 33, n. 4, p. 711-728, 2004.

TENÓRIO, Fernando Guilherme. Um espectro ronda o terceiro setor: o espectro do mercado. Revista de administração pública, v. 33, n. 5, p. 85-102, 1999.

TENÓRIO, Fernando Guilheme. Gestão de ONGs: principais funções gerenciais. Rio de Janeiro: FGV, 2005. 